\title{
Der konsultative Staat. Reformpolitik und Politikberatung
}

Isabelle Roth

Rezension von Lamping, Wolfram; Schridde, Henning (2011): Der konsultative Staat. Reformpolitik und Politikberatung. Verlag Barbara Budrich: Opladen \& Farmington Hills, MI.

Der Band ist einerseits als Festschrift für Bernhard Blanke konzipiert und andererseits als Tagungsband zum Abschluss „der über 25-jährigen Forschungs- und Transferarbeit“ der Abteilung Sozialpolitik und Public Policy am sozialwissenschaftlichen Institut der Universität Hannover (S. 14). Grundlegend thematisiert das Werk zwei Hauptthemen. Erstens steht das Verhältnis von Politik und Wissenschaft unter dem Gesichtspunkt nach dem Beratungspotenzial von Politik durch Wissenschaftler im Fokus und die Frage wie beratbar Politik und wie beratungsfähig Wissenschaft ist. Zweitens stehen die Sozialstaatreform und Sozialpolitik im Sinn der inhaltlichen Ausrichtung der Abteilung Blankes im Zentrum der Betrachtung. Die Einleitung zum Verhältnis von Wissenschaft, Politik und deren Beratung kompensiert das Fehlen einer Zusammenfassung, da sie synoptisierende Funktionen übernimmt und einen umfassenden Überblick über das Gebilde „konsultativer Staat" liefert. Weil der Band sehr umfassend angelegt ist, werden nur einige Aufsätze besprochen.

Die Einleitung der Herausgeber nimmt über eine zusammenfassende Darstellung der Beiträge hinaus deren Hauptthesen und Argumentationsgänge bereits voraus und systematisiert diese. Dies geschieht unter der Klammer eines Verständnisses vom „konsultativen Staat“, welches nicht nur als Chiffre für den evolutionär vorangetriebenen Formenwandel von Staatlichkeit verstanden wird (S. 12-13), sondern in welchem sich gerade Politikberatung eignet, politische Entscheidungsunsicherheit zu reduzieren (S. 22). Insofern wird mit einem doppelt verstandenen Sinn von Konsultation operiert: Es stellt sich zentral die Frage, wer im Gefüge von Staat und Politikberatung „Berater“ und wer „Beratener“ ist (S. 13).

Frank Nullmeiers Interpretation Max Webers im Sinne der „Politikberatung als Nebenberuf“ thematisiert Politikberatung durch Wissenschaft. Dabei versteht er Politikberatung als „jede Art der privilegierten Bezugnahme auf in besonderem Maße autorisiertes Wissen im Felde der Politik“ (S. 40). Eine Form dieses Wissens stellt Wissenschaft dar, welche einen Betrieb im Sinne eines Übergangsfeldes ausbildet (S. 43).

$\mathrm{Zu}$ den verschiedenen Rollen des Politikers sowie des beratenden Wissenschaftlers diskutiert Hubert Heinelt „drei Welten demokratischen Handelns“ (S.48), welche Ebenen des Regierens darstellen und die Einbettung von Wissen in Entscheidungsprozesse mitprägen. Seine Gegenüberstellung der Handlungsorientierungen und -optionen von Wissenschaftlern und Politikern charakterisiert er als Habitus des „romantischen Ironikers“, welchen Wissenschaftler einnehmen kön- nen, Politiker aber verbergen (S. 56), weil von ihnen Antworten erwartet werden.

Jobst Fiedler betrachtet Management- und Politikberatung vergleichend und kommt zu dem Schluss, dass mit der Schuldenkrise die Notwendigkeit von Managementberatung „erheblich an Relevanz für die politische Leitungsebene“ (S. 246) gewinnen werde.

Fritz B. Simon nimmt Aspekte der Politikberatung und der Unterschiedlichkeit von Wissenschaftlern und Politikern in einen systemtheoretischen Blick. Dabei müsse der Politikwissenschaftler oft die Erfahrung Kassandras machen, „die Logik und Dynamik politischer Prozesse zu durchschauen meint“, „aber es wird nicht auf ihn gehört“ (S. 269).

Jörg Bogumil rundet den Band mit einer Betrachtung von Regierung und Bürgerpartizipation auf der kommunalen Ebene ab. Er arbeitet die Verantwortungsteilung zwischen Staat und Gesellschaft heraus und zeigt, dass die Kooperation und Koproduktion zwischen bürgergesellschaftlichen Organisationen und staatlichen Akteuren zentral im Sinne einer „Anwender-Demokratie“ sind um Initiativen durch Selbstorganisation zu erhalten oder zu optimieren (S. $288 \mathrm{f}$.).

Die Beiträge zeigen, dass es beim Verhältnis von Staat, Politik und Verwaltung weniger ein „Entweder-oder“ gibt, sondern feine Nuancen eines „konsultativen Staates“ zwischen ratsuchend und Rat gebend. Insofern deckt der Band auch aufgrund des breiten Spektrums der Beiträger (vom Professional bis zum Professor) - ein weites Feld ab und ist für Praktiker, die an der Verknüpfung von Wissenschaft, Politik und Sozialem interessiert sind, eine instruktive Lektüre.

Isabelle Roth Universität Trier rothi@uni-trier.de 